\title{
Investigation of Lipid Oxidation in the Raw Materials of a Topical Skin Formulation: A Topical Skin Formulation Containing a High Lipid Content
}

Thomsen, Birgitte Raagaard; Taylor, Richard; Madsen, Robert; Hyldig, Grethe; Blenkiron, Peter; Jacobsen, Charlotte

Published in:

Journal of the American Oil Chemists' Society

Link to article, DOI:

10.1002/aocs. 12015

Publication date:

2018

Document Version

Peer reviewed version

Link back to DTU Orbit

Citation (APA):

Thomsen, B. R., Taylor, R., Madsen, R., Hyldig, G., Blenkiron, P., \& Jacobsen, C. (2018). Investigation of Lipid Oxidation in the Raw Materials of a Topical Skin Formulation: A Topical Skin Formulation Containing a High Lipid Content. Journal of the American Oil Chemists' Society, 95(2), 185-196. https://doi.org/10.1002/aocs.12015

\section{General rights}

Copyright and moral rights for the publications made accessible in the public portal are retained by the authors and/or other copyright owners and it is a condition of accessing publications that users recognise and abide by the legal requirements associated with these rights.

- Users may download and print one copy of any publication from the public portal for the purpose of private study or research.

- You may not further distribute the material or use it for any profit-making activity or commercial gain

- You may freely distribute the URL identifying the publication in the public portal 
1 Investigation of lipid oxidation in the raw materials of a topical skin formulation: A topical skin formulation containing a high lipid content. Authors: Thomsen, B.R. ${ }^{1}$, Taylor, R. ${ }^{2}$, Madsen, R. ${ }^{3}$, Hyldig, G. ${ }^{1}$, Blenkiron, P. ${ }^{2}$ and Jacobsen, C. ${ }^{1 *}$

$4{ }^{1}$ National Food Institute, Division of Food Technology, Technical University of Denmark, Lyngby,

5 DK, ${ }^{2}$ Glaxo Smith Kline, Brentford, UK, ${ }^{3}$ Department of Chemistry, Technical University of

6 Denmark, Lyngby, DK

\section{Keywords}

8 Oxidative Stability, Nutrition and Health, Autoxidation, Lipid Chemistry, Lipid Analysis and Lipids

\section{Abstract}

10 Several studies have demonstrated that lipid oxidation often occurs in topical skin formulations which 11 can affect product odour (both positively and negatively). Furthermore, odour detection threshold 12 values and odour descriptors of identified volatile oxidation products in cleansing and skin cream 13 formulation prototypes were recently determined by a trained sensory panel at the Technical 14 University of Denmark in the Division of Food Technology. In this study, we investigated lipid 15 oxidation in a prototype skin cream formulation as well as in selected cosmetic skin care raw 16 materials. Lipid oxidation was measured regularly over a six-month period for the product and over a 17 three-month period for the raw materials by headspace gas chromatography-mass spectrometry. The 18 volatile compound present in the highest initial concentration, and which increased most during 19 storage, was 3-methyl-1-butanol (medicinal, chemical/cleaning agent odour), and its formation was 20 linked to the raw material isoamyl p-methoxycinnamate. The odour character of the product after 21 storage was assessed and informally deemed acceptable for consumer usage and typical of topical 22 dermocosmetic products. A potential pathway for its formation was also identified. In addition, the 23 concentrations of several well-known lipid oxidation products increased during storage and were 24 suggested to originate primarily from rice bran wax, which oxidized more readily than other raw 25 materials due to its unsaturated nature.

\section{Introduction}

27 Several studies have shown that lipid oxidation often occurs in topical skin care formulations 28 containing unsaturated lipids and that lipid oxidation products can affect product quality (1-6) (i.e. 29 odour (4-6) and colour (2)), potentially impacting product both positively and/or negatively. 
30 Earlier studies have shown that raw materials were at least partly responsible for volatile compounds

31 present in simple emulsions immediately after their production $(7,8)$. Since topical skin care

32 formulations are often emulsions, knowledge obtained from studies on simple emulsions can provide some understanding of the mechanisms behind the formation of volatile compounds in topical products. However, the composition of topical skin care formulations is far more complex than that of simple emulsion systems and so are the oxidation mechanisms. In order to determine whether/which raw materials are responsible for volatile compounds present in freshly produced topical skin formulations, several factors must be considered: volatiles introduced by raw materials, production method (e.g. temperature and other processing conditions as well as exposure to oxygen and light), and the mechanisms leading to the formation of volatile compounds (7-12). Volatile lipid oxidation products can also be formed during storage as a result of interactions between raw materials, production method and storage conditions. Temperature and exposure to oxygen and light during storage are factors that can influence the rate of lipid oxidation after production.

Other studies have investigated the effect of impurities in raw materials on oxidative stability in finished food products and model emulsions, as summarised in a review by Waraho et al. (12), who concluded that the oxidative stability of the finished product was linked to the quality of the raw materials. Since some raw materials used in foods are common with cosmetics, studies performed on raw materials for food can be used as guidance for cosmetics.

In a study on raw materials for personal care products, the impact of the production method on the quality of myristyl myristate, a skin conditioning and opacifying agent, was explored (13). The purity of myristyl myristate products varied from $80.1 \%$ to $97.5 \%$ between manufacturers. Furthermore, the oxidative status of the myristyl myristate products measured by peroxide value (PV) fluctuated from $<0.1$ to $6.0 \mathrm{meq} / \mathrm{kg}$ depending on the manufacturer and product grade. In addition, the colour, acid value $(0.2-0.8 \mathrm{mg} / \mathrm{g})$, hydroxyl value $(1.6-14.0 \mathrm{mg} / \mathrm{g})$ and saponification value $(128-134 \mathrm{mg} / \mathrm{g})$ also varied widely between the production methods used (13).

60 The aim of this study was to explore lipid oxidation in selected raw materials and in a topical skin 61 formulation containing high levels of lipids. A second aim was to correlate any raw material oxidation 
62 with the finished product oxidation to identify any culpable agents. In addition, we aimed to

63 understand the mechanism leading to the formation of any identified volatile compounds.

64 Materials

65 Prototype Skin Cream Formulation (PSCF)

66 The prototype skin cream formulation was produced by GlaxoSmithKline (Brentford, United 67 Kingdom) and contained several raw materials including rice bran wax, glycerine, isostearyl 68 isostearate, palmitic acid monoethanolamine (PMEA). The prototype skin cream formulation contained approximately $29 \%$ of lipid.

70

71

$\underline{\text { Raw materials }}$

Separately to the aforementioned prototype product, individual (cosmetic-industry-relevant) raw materials were assessed for lipid oxidation potential:

- Rice bran wax (Koster Keunen, Bladel, Netherlands),

- Glycerine (Croda Europe Ltd, East Yorkshire, England),

- Isostearyl isostearate (Croda Europe Ltd, East Yorkshire, England),

- Palmitic Acid Monoethanolamine (PMEA; Jan Dekker, Wormerveer, Netherlands),

- Isoamyl p-methoxycinnamate (UV cinnamate) (Symrise AG, Holzminden, Germany),

- Bis-ethylhexyloxyphenol methoxyphenyl triazine (UV triazine) (BASF SE, Ludwigshafen, Germany),

- Hexyl 2-(1-(diethylaminohydroxyphenyl)methanoyl)benzoate (UV benzoate) (BASF SE, Ludwigshafen, Germany).

\section{Methods}

\section{$\underline{\text { Storage conditions }}$}

PSCF was stored for 6 months at $5^{\circ} \mathrm{C}, 20^{\circ} \mathrm{C}$ and $40^{\circ} \mathrm{C}$ without exposure to light and at $20^{\circ} \mathrm{C}$ with exposure to light and for 2 weeks at $50^{\circ} \mathrm{C}$. Samples were taken after $0,1 / 2,1,2,3$ and 6 months.

Raw materials were stored at $40^{\circ} \mathrm{C}$ for 3 months; samples were taken after $0,1,2$ and 3 months of storage. 
88 The samples were stored in closed $40 \mathrm{ml}$ opaque bottles. Samples were stored in individual bottles, to

89 be withdrawn at each time point for each analysis. After sampling, all samples were stored at $5^{\circ} \mathrm{C}$ until 90 analysis.

$91 \quad$ Oil extraction methodology

92 Oil was extracted from $5 \mathrm{~g}$ of PSCF and UV cinnamate with the Bligh and Dyer method $(15)(\mathrm{n}=2)$. 93 However, a reduced amount of solvent was applied as described by Iverson et al. (16). In brief, lipids 94 were extracted by the use of a homogenous mixture of $20 \mathrm{ml}$ of chloroform, $20 \mathrm{ml}$ of methanol and 15 $95 \mathrm{ml}$ of water. The water soluble parts were separated from the lipid soluble parts by a subsequent 96 addition of chloroform and methanol. Phase separation was completed by centrifugation. After phase 97 separation was completed, chloroform in the chloroform and lipid phase was evaporated, and the oil 98 content could then be determined gravimetrically. The lipid extract was used as the starting material 99 for analysis of PV and determination of fatty acid composition.

100

\section{Determination of Peroxide Value}

PV was measured using the IDF method (17) and quantified by colorimetric determination of iron thiocyanate spectrophotometrically at $500 \mathrm{~nm}$ by UV mini 1240 (Shimadzu, Duisburg, Germany) (n= 2). The spectrophotometer was reset to detect chloroform/methanol (7:3) solvent as zero.

\section{Quantification of volatile compounds}

Extraction of volatile compounds, GC-MS analyses and quantification were done automatically as described by Thomsen et al. (18) with the following modification of the sample preparation, collection and water evaporation (Table 1). These modifications were done in order to extract volatile compounds from all matrices, to avoid contamination of the tube by powders and to remove water residues.

Briefly, volatile compounds were collected from $1 \mathrm{~g}$ of sample in a $10 \mathrm{~mL}$ vial $(\mathrm{n}=3)$. The automation sequence was: incubation for $4 \mathrm{~min}$ at a temperature of $60^{\circ} \mathrm{C}$ or $45^{\circ} \mathrm{C}$ (see Table 1). The sample was agitated at $300 \mathrm{rpm}$ (agitator on time: $10 \mathrm{~s}$, agitator off time: $1 \mathrm{~s}$ ). Thereafter, purging with nitrogen at $50 \mathrm{ml} / \mathrm{min}$ through the headspace of the vial was started for $20 \mathrm{~min}$. The volatile compounds were trapped on tubes containing Tenax GR 300 (Gerstel GmbH \& Co. KG., Mülheim an der Ruhr, Germany). Water residues were removed from the tubes with a $50 \mathrm{~mL} / \mathrm{min}$ purge flow (see Table 1). Then the volatile compounds were desorbed from tubes in the thermal desorption unit (initial temp 40 ${ }^{\circ} \mathrm{C}$, then $720{ }^{\circ} \mathrm{C} / \mathrm{min}$ to $280{ }^{\circ} \mathrm{C}$ kept there for $5 \mathrm{~min}$ ) to the GC. The volatile compounds were analysed 
118 on a GC-MS model: HP 6890 - HP 5973 (Agilent Technologies, USA). Chromatographic separation 119 was performed on a DB1701 column $(30 \mathrm{~m} \times$ ID $0.25 \mathrm{~mm} \times 0.5 \mu \mathrm{m}$ film thickness, J\&W Scientific, 120 Folsom, CA, USA) using helium gas flow $(1.3 \mathrm{~mL} / \mathrm{min})$ in the GC. The MS settings were: $70 \mathrm{eV}$, 121 electron ionization mode, mass to charge ratio $(\mathrm{m} / \mathrm{z})$ scan between 30 and 250 . The GC temperature122 program was as follows: initial $45^{\circ} \mathrm{C}, 5^{\circ} \mathrm{C} / \mathrm{min}$ until $90^{\circ} \mathrm{C}, 4^{\circ} \mathrm{C} / \mathrm{min}$ to $220^{\circ} \mathrm{C}$ and held for $4 \mathrm{~min}$.

\section{Fatty acid methyl esters (FAME)}

124 Fatty acid compositions in oil and Bligh and Dyer extracts were determined as described by Safafar $e t$ 125 al. (19) $(\mathrm{n}=2)$. In brief, $1 \mathrm{~g}$ of Bligh and Dyer extract or $0.3 \mathrm{~g}$ of oil were weighed in test tubes. The 126 chloroform was evaporated from Bligh and Dyer extract with nitrogen. Then, internal standard 23:0 127 was added to the oil and extracted together with heptane with BHT, toluene and borontrifluoride in 128 methanol. Samples were mixed and methylated in a microwave oven (Microwave 3000 SOLV, Anton 129 Paar, Ashland, VA, USA) and then cooled down. Saturated $\mathrm{NaCl}$ and heptane with BHT were added 130 and thereafter phase separation occurred. The upper phase of the sample was transferred into $1 \mathrm{~mL}$ 131 vials and analysed by Agilent 7890A gas chromatograph (Agilent Technologies, Palo Alto, CA, USA) 132 with a DB-WAX fused silica capillary column $(10 \mathrm{~m} \times 0.1 \mathrm{~mm}, 0.1 \mu \mathrm{m}$; Agilent Technologies, Palo 133 Alto, CA, USA), helium as carrier gas and a flame ionization detector. The GC temperature program: 134 initial $160^{\circ} \mathrm{C}, 10.6^{\circ} \mathrm{C} / \mathrm{min}$ until $200^{\circ} \mathrm{C}$ and held for $0.3 \mathrm{~min}, 10.6^{\circ} \mathrm{C} / \mathrm{min}$ to $220^{\circ} \mathrm{C}$ and held for $1 \mathrm{~min}$, 135 and $10.6^{\circ} \mathrm{C} / \mathrm{min}$ to $240^{\circ} \mathrm{C}$ and held for $3.8 \mathrm{~min}$. Fatty acids were identified by comparing their 136 retention time to that of authentic standards. Fatty acids were expressed as $\%$ fatty acid of total fatty 137 acids from $\mathrm{C} 8-\mathrm{C} 24$.

138 pH determination

139 The $\mathrm{pH}$ was measured using a Metrohm $827 \mathrm{pH}$ meter (Metrohm, Herisau, Switzerland).

140 Description of difference scale

141 An expert panel of 3 scientists conducted a fast industry standard method to assess the odour changes. 142 In this method, the sample odour was graded versus a reference sample stored at $5^{\circ} \mathrm{C}$. The samples 143 were ranked from one to five based on a scale description of difference (DOD) between sample and 144 reference sample (Table 2). All samples ranked three or less were deemed within product range.

$145 \quad$ Statistical analysis 
146 A two-way analysis of variance and a Bonferroni multiple comparison test were employed to evaluate

147 significant changes in Figure 1 and 2. The significance level was 0.05 . The statistical analysis was

148 conducted using Graph Pad Prism version 6 (Graph Pad, La Jolla, USA).

\section{Results and discussion}

\section{Lipid oxidation in PSCF: PV and volatile analysis}

151 PV was used as a measurement of the primary oxidation products, lipid hydroperoxides. PV was 152 initially $0.62 \pm 0.01 \mathrm{meq} / \mathrm{kg}$ and remained below $0.65 \mathrm{meq} / \mathrm{kg}$ during the 6 months of storage at $5^{\circ} \mathrm{C}$, $15320^{\circ} \mathrm{C}$ and $40^{\circ} \mathrm{C}$ (data not shown). When exposed to light during storage, the PV increased slightly to $1541.44 \pm 0.17 \mathrm{meq} / \mathrm{kg}$. According to PV, lipid oxidation only occurred to a low extent. However, a low 155 PV does not necessarily imply that no oxidation has occurred; it may be related to rapid conversion of 156 lipid hydroperoxides to secondary volatile oxidation products. It is therefore also advisable to assay for 157 secondary lipid oxidation products.

158 The assay for secondary volatile oxidation products, via dynamic headspace GC-MS analysis, 159 confirmed that the low PV was due to a fast conversion to aldehydes and alcohols. The concentration 160 for the following volatile aldehydes increased significantly during storage (Figure 1): butanal, 3161 methylbutanal, pentanal, hexanal, benzaldehyde and octanal. Butanal, pentanal, hexanal and octanal

162 are all well-known lipid oxidation products. 3-methylbutanal and benzaldehyde have been suggested to 163 originate from non-enzymatic browning reactions (20-22). Butanal, 3-methylbutanal, pentanal and 164 hexanal increased to a greater extent during storage at $20^{\circ} \mathrm{C}$ and $40^{\circ} \mathrm{C}$ without exposure to light and at $16520^{\circ} \mathrm{C}$ with exposure to light than at $5^{\circ} \mathrm{C}$ (Figure 1A-D). Unexpectedly, benzaldehyde and octanal 166 increased most during storage at $20^{\circ} \mathrm{C}$ without exposure to light followed by $20^{\circ} \mathrm{C}$ with exposure to 167 light.

168 In an earlier study, we determined odour detection threshold values for lipid oxidation products, which 169 is the concentration at which the volatile compounds start to affect product odour. However, these 170 were only determined for the volatile compounds that increased during storage in a PSCF. In general, 171 we found that odour detection threshold values in PSCF were above $70 \mathrm{ng} / \mathrm{g}(5,6)$. Therefore, volatile 172 compounds present in concentrations below $70 \mathrm{ng} / \mathrm{g}$ were not considered to affect product odour when 173 present alone (3-methylbutanal and octanal) in the current study.

174 The odour detection threshold value determined for butanal was $72 \pm 3 \mathrm{ng} / \mathrm{g}(5,6)$. In the present study, 175 the concentration was above this level after 3 months storage at $20^{\circ} \mathrm{C}, 20^{\circ} \mathrm{C}$ with exposure to light or 
$17640^{\circ} \mathrm{C}$, and after 6 months at $5^{\circ} \mathrm{C}$ (Figure 1A). Butanal odour in PSCF has been described as parmesan 177 and sour dishcloth $(5,6)$.

178 The odour detection threshold value for pentanal $(87 \pm 5 \mathrm{ng} / \mathrm{g})$ was slightly higher compared with 179 butanal $(5,6)$. The concentration was above this level after 3 months at $20^{\circ} \mathrm{C}$ with exposure to light (at $18092 \mathrm{ng} / \mathrm{g}$ ) or $40^{\circ} \mathrm{C}$ (at $104 \mathrm{ng} / \mathrm{g}$ ), and after 6 months at $20^{\circ} \mathrm{C}$ or $5^{\circ} \mathrm{C}$ (Figure $1 \mathrm{C}$ ). Pentanal odour in 181 PSCF has been described as green and milk acidic $(5,6)$. The odour detection threshold value for 182 hexanal has not been determined in PSCFs. Based on the odour detection threshold values obtained for 183 butanal and pentanal, it is estimated to be above $90 \mathrm{ng} / \mathrm{g}$. Hexanal concentrations were above this level 184 after 6 months of storage at all storage conditions. In literature, its odour has been described as fatty, 185 green and fresh $(23,24)$. In addition to aldehydes, a few alcohols and ketones increased as well (Figure 186 2).

187 The concentration of 3-methyl-1-butanol was significantly above its odour detection threshold value of $1881926 \pm 316 \mathrm{ng} / \mathrm{g}$ after 6 months of storage. Odour detection threshold values have not been determined 189 for the ketones. However, none of the ketones increased to concentrations above $70 \mathrm{ng} / \mathrm{g}$. Therefore, it 190 is assumed that these ketones did not affect product odour. In a previous study, 3-methyl-1-butanol 191 was described with the odour of glue, rubber, chemical, medicine, cleaning agent $(5,6)$. An expert 192 panel of 3 scientists conducted a DOD sensory evaluation to assess the odour changes, PSCF increased 193 in intensity of chemical and cleaning agent, and scored 3 on the DOD scale after 6 months storage with 194 exposure to light and at $40^{\circ} \mathrm{C}$. Since many volatile compounds were present from the beginning of the 195 storage period, they may originate directly from raw materials. Selected raw materials were explored 196 to link volatile compounds in PSCF to those present in raw materials.

\section{Lipid oxidation in selected raw materials}

198 One of the primary functions of a cream is to moisturise and protect the skin so they often contain high 199 levels of lipids, but unsaturated lipids can oxidize and form volatile compounds. Several volatile 200 compounds were present initially in the lipid ingredients and more were generated during accelerated 201 storage at $40^{\circ} \mathrm{C}$ in the following ingredients: rice bran wax and glycerine (Figure 3A and 3B). PSCF 202 also contained D-panthenol, which was very stable during accelerated storage. Thus, benzaldehyde 203 was the only volatile aldehyde that could be detected and this was not possible until 3 months of 204 storage when $139 \pm 9 \mathrm{ng} / \mathrm{g}$ was detected (data not shown).

205 Initially, some raw materials (rice bran wax and glycerine) contained several aldehydes and thus 206 contributed to the initial concentration of all 10 volatile compounds detected in PSCF. Two raw 
materials, rice bran wax and glycerine, contained butanal and contributed to the presence of this volatile compound in the freshly produced PSCF. Furthermore, rice bran wax contained 1-pentanol at $262 \mathrm{ng} / \mathrm{g}$ and 2-pentanone at $6 \mathrm{ng} / \mathrm{g}$ after accelerated storage. Therefore, it is likely that these two raw materials contributed to the development of 1-pentanol and 2-pentanone in PSCF. Moreover, the initial content of pentanal, 3-methylbutanal, 2-hexanone and hexanal in PSCF originated partly from rice bran wax and glycerine. The last aldehyde, benzaldehyde, may originate from D-panthenol (data not shown), rice bran wax and glycerine.

Only low concentrations of volatile compounds were present in glycerine compared with rice bran wax. Glycerine can oxidize to aldehydes such as glyceraldehyde in presence of metal ions and elevated temperature. Overall, 11 different oxidation products that have a three carbon structure have been identified for glycerine. However, the oxidation products can react with other molecules to form compounds with more than three carbons. One proposed mechanism is a reaction between glyceraldehyde and glycerine to form glycerine acetate described by Jungermann and Sonntag (25). Another possibility is simple polymerisation. The purity of glycerine was $99.5 \%$. Moreover, the impurities may also contribute to the volatile compounds developing during accelerated storage.

Rice bran wax (mostly wax esters) mainly contained saturated fatty acids (86\%; 16:0,18:0, 20:0, 22:0 and $24: 0)$, in addition to monounsaturated $(6.5 \% ; 18: 1 \mathrm{n}-9)$ and polyunsaturated fatty acids $(3 \% ; 16: 3$ n-4, 18:2 n-6, 20:3 n-6 and 20:4 n-6). Despite a low concentration of polyunsaturated fatty acids, rice bran wax had significantly higher concentrations of most volatile compounds detected than glyerine because polyunsaturated fatty acids were highly susceptible to auto-oxidation. Auto-oxidation of polyunsaturated fatty acids gives rise to formation of primary oxidation product which can decompose further to secondary oxidation products. One of most likely decomposition pathways is scission. Scission (either $\alpha$ or $\beta$ ) results in a complex mixture of secondary oxdation products inclunding the measured alcohols, ketones and aldehydes $(21,22)$.

The following two raw materials, PMEA and isostearyl isostearate, work as skin conditioners in PSCF. Initially, only hexanal, butanal and pentanal were present in PMEA and isostearyl isostearate (Figure 4), and they may thus partly be responsible for the initial presence of hexanal in PSCF.

Several volatile compounds appeared in the raw materials during the 3 months of storage, but some of these volatile compounds only appeared in PMEA and isostearyl isostearate (2-heptanone, heptanal and nonanal) (Figure 4). However, all 10 volatile compounds that increased during storage in PSCF also appeared and increased in isostearyl isostearate and PMEA, namely butanal, 3-methylbutanal (only isostearyl isostearate), pentanal, 2-pentanone, 1-pentanol (only isostearyl isostearate), 3-methyl- 
239 1-butanol (only isostearyl isostearate), hexanal, 2-hexanone, octanal and benzaldehyde (only PMEA).

240 Therefore, it is likely that PMEA and isostearyl isostearate contributed to the increase observed in

241 PSCF of most of the volatiles. The structure of both PMEA and isostearyl isostearate did not indicate a

242 clear reactive group/site, which can result in the observed volatile compounds. More studies are

243 therefore needed to understand where they originate from. Their presence may be related to impurities

244 present in the raw materials.

245 The last raw materials included in this study were UV filters. These raw materials were produced with 246 the purpose of being reactive towards pro-oxidants. Three UV filters were investigated: UV benzoate, 247 UV triazine and UV cinnamate. Initially, only a small amount of octanal was present in UV benzoate, 248 and UV triazine did not contain any known oxidation products (Figure 5).

249 After 3 months of accelerated storage, aldehydes predominantly formed in UV benzoate and UV 250 triazine. Some of the volatile compounds that appeared during the 3 months of storage were not 251 present in PSCF (heptanal and nonanal). UV benzoate and UV triazine generated butanal, 3-

252 methylbutanal (only UV benzoate), pentanal, hexanal, 2-hexanone, octanal and benzaldehyde after 3 253 months storage.

254 In contrast to the other two UV filters, UV cinnamate contained substantial amounts of 3-methyl-1255 butanol initially, and the concentration of this compound increased further during storage (Figure 5). In 256 addition, UV cinnamate also generated 3-methylbutanal during storage. After three months of 257 accelerated storage, octanal $28 \mathrm{ng} / \mathrm{g}$, pentanal $42 \mathrm{ng} / \mathrm{g}$ and benzaldehyde $495 \mathrm{ng} / \mathrm{g}$ appeared as well 258 (Figure 5C). Although several aldehydes occurred after three months of storage, their concentrations 259 were low in UV filters compared with the concentrations in humectant, skin texture modifying and 260 skin conditioning raw materials. Therefore, UV benzoate and UV triazine were not explored further. 261 However, the high concentration of 3-methyl-1-butanol generated by UV cinnamate would be 262 expected to impact a finished product odour. A trained sensory panel described 3-methyl-1-butanol as 263 glue, rubber, chemical, medicine and cleaning agent $(5,6)$. Therefore, it is important to understand the 264 route of reactions leading to 3-methyl-1-butanol in order to identify ways to control it.

265 MacManus-Spencer et al. (26) have previously investigated the degradation of octyl p266 methoxycinnamate under photolytic conditions and identified 4-methoxybenzaldehyde and 2267 ethylhexanol among the products. Two cleavage routes were considered in their work where the alkene 268 in the UV-filter either reacted with water followed by a retro-aldol reaction or a reaction occurred with 269 singlet oxygen to form the aldehydes through an unstable dioxetane (26). The same pathways can be 270 envisioned in our case where UV cinnamate either would form 4-methoxybenzaldehyde and isoamyl 
271 acetate by reaction with water or undergo a cleavage with singlet oxygen to give the corresponding 272 aldehydes (Scheme 1). The addition of water to cinnamates followed by a retro-aldol reaction is a 273 known biosynthetic pathway in the synthesis of plant benzoic acids from cinnamates (27). As a result, 274 it should also be a feasible chemical route although the transformation is probably very slow. The 275 cleavage of olefins by singlet oxygen is well-known (28-30) and the formed isoamyl ester of glyoxylic 276 acid is presumably labile enough to hydrolyse completely under the storage conditions (31). Finally, 277 direct hydrolysis of UV cinnamate to the carboxylic acid and 3-methyl-1-butanol should also be 278 included in the considerations (Scheme 1).

279 In addition to 3-methyl-1-butanol the degradation of UV cinnamate may thus also form 4280 methoxybenzaldehyde and isoamyl acetate which can be used to distinguish between the different 281 pathways. The $\mathrm{pH}$ of UV cinnamate was 4.23 initially and decreased slightly to 4.01 after 3 months 282 storage at $40^{\circ} \mathrm{C}$. Inspection of the chromatograms from UV cinnamate did indeed reveal the presence 283 of both 4-methoxybenzaldehyde and isoamyl acetate. The retention time was 31.887 for 4284 methoxybenzaldehyde and 14.024 for isoamyl acetate and both signals were confirmed by external 285 standards. Notably, the acetate of the alcohol was not detected in the earlier work by MacManus286 Spencer et al. (26). 4-Methoxybenzaldehyde and isoamyl acetate were both present in UV cinnamate 287 from the beginning of the storage period and their amounts increased further during storage. Although, 288 the two by-products have not been quantified by the use of calibration curves, they appear to be 289 formed in somewhat equal amounts and certainly to a much lesser degree than 3-methyl-1-butanol, 290 which is the main by-product. As a result, 4-methoxybenzaldehyde and 3-methyl-1-butanol cannot be 291 formed by the oxidative cleavage with singlet oxygen since this would give rise to similar amounts of 292 both compounds. Instead, it is very likely that 4-methoxybenzaldehyde and isoamyl acetate are formed 293 by the addition of water and a retro-aldol reaction.

294 This leaves the direct hydrolysis of the ester as the main pathway for the formation of 3-methyl-1295 butanol. It is known that esters can hydrolyse under near neutral conditions, but the reaction is very 296 slow. For ethyl cinnamate the half-life for hydrolysis in water at $\mathrm{pH} 4.0$ and $25^{\circ} \mathrm{C}$ is estimated to be 297 about 100 years (32). This number will be higher for UV cinnamate in the present case since the 298 hydrolysis is slower in a non-polar environment. However, the amount of 3-methyl-1-butanol released 299 in Figure 5 only corresponds to about $0.2 \%$ (w/w) after 3 months storage at $40^{\circ} \mathrm{C}$. Therefore it is 300 hypothesised that this is a result of a very slow direct hydrolysis of the ester in the UV-filter under the 301 near neutral conditions. 
303 Linking volatiles in PSCF with those in raw materials

304 The volatile compounds present in PSCF and raw materials are summarized in Table 3. In brief, the

305 increase observed in butanal in PSCF during storage may mainly originate from isostearyl isostearate,

306 for which the concentration was above odour detection threshold value from the beginning of the 307 storage. However, butanal also developed in rice bran wax, glycerine, PMEA, UV triazine and UV 308 benzoate during storage.

309 The formation of 3-methylbutanal was related to several raw materials, namely, rice bran wax, 310 glycerine, isostearyl isostearate, UV cinnamate and UV benzoate. The concentration of pentanal 311 increased in all raw materials and the concentration was above odour detection threshold value in rice 312 bran wax, isostearyl isostearate and PMEA after 3 months of storage. Hexanal increased significantly 313 in the PSCF during storage and also increased to high concentrations in rice bran wax and PMEA 314 (more than $150 \mathrm{ng} / \mathrm{g}$ ). In addition, hexanal was present in glycerine, isostearyl isostearate, UV triazine 315 and UV benzoate in low concentrations (less than $70 \mathrm{ng} / \mathrm{g}$ ). Benzaldehyde mainly increased in PSCF at $31620^{\circ} \mathrm{C}$ with exposure to light to $112 \mathrm{ng} / \mathrm{g}$ after 6 months' storage. It was possible to relate benzaldehyde 317 to all raw materials except isostearyl isostearate. The last aldehyde octanal appeared in all raw 318 materials except glycerine during accelerated storage. Particularly the concentration of octanal 319 increased in rice bran wax. The alcohol 1-pentanol marginally increased in a few materials, rice bran 320 wax and isostearyl isostearate. In contrast, to the low concentration of 1-pentanol and 3-methyl-1321 butanol in isostearyl isostearate, 3-methyl-1-butanol was present in high concentration in PSCF from 322 the beginning and throughout the storage period. The RMs shown to generate 3-methyl-1-butanol 323 during storage were UV cinnamate, glycerine and isostearyl isostearate. Lastly, the two ketones, 2324 pentanone and 2-hexanone, were present in both PSCF and several raw materials but only in low 325 concentrations.

326 GSK Toxicology group (2017) has assessed the human safety impact of the volatiles included in this 327 report. At the determined levels these substances do not raise any toxicological concern, neither locally 328 or systemically (33).

\section{Conclusion}

330 This study explored lipid oxidation and oxidative degradation in a topical skin formulation (PSCF) 331 containing high levels of lipid. Some secondary volatile oxidation products were present initially and 332 more were generated during the 6 months of storage. Most notably, 3-methyl-1-butanol was present in 333 a high concentration initially and it increased further during storage. Since the concentration of 3- 
334 methyl-1-butanol was higher than the odour detection threshold value after six months of storage, it 335 was expected to affect product odour after long term storage, generating an increase in the medicinal, 336 chemical/cleaning agent-type odour character. This product was therefore assessed for odour changes 337 (informally vs. a $5^{\circ} \mathrm{C}$ control sample) and deemed acceptable and typical of a dermocosmetic product, 338 highlighting again the importance of considering the combination effect (of other volatiles present) and 339 the product base odour when interpreting the impact of any lipid oxidation on product odour.

340 Selected raw materials were explored in order to link volatile compounds affecting the quality in the 341 topical skin formulation to raw material(s). The UV cinnamate filter developed high levels of 3342 methyl-1-butanol during storage so was identified as a material to control. A potential pathway leading 343 to 3-methyl-1-butanol was proposed.

344 Furthermore, well-known lipid oxidation products and non-enzymatic browning products were 345 suggested to originate from rice bran wax in particular because of its unsaturated nature. It was 346 surprising that volatile lipid oxidation products occurred in PMEA and isostearyl isostearate, as these 347 raw materials did not contain reactive sites for oxidation. More studies are needed to explore why 348 volatile compounds appeared. 


\section{References}

351 1. Thanonkaew A, Wongyai S, Decker EA, McClements DJ (2015) Formation, antioxidant 352 property and oxidative stability of cold pressed rice bran oil emulsion. J Food Sci Technol $353 \quad 52: 6520-6528$

354 2. Poyato C, Thomsen BR, Hermund DB, Ansorena D, Astiasarán I, Jónsdóttir R, Jacobsen C 355 (2017) Antioxidant effect of water and acetone extracts of Fucus vesiculosus on oxidative $356 \quad$ stability of skin care emulsions. Eur J Lipid Sci Technol 119:1600072

357 3. Malinowska P, Gliszczynska-swiglo A, Szymusiak H (2014) Protective effect of commercial 358 acerola, willow, and rose extracts against oxidation of cosmetic emulsions containing wheat 359 germ oil. Eur J Lipid Sci Technol 116:1553-1562

360 4. Thomsen BR, Horn AF, Hyldig G, Taylor R, Blenkiron P, Jacobsen C (2017) Investigation of 361 lipid oxidation in high- and low-lipid-containing topical skin formulations. J Am Oil Chem Soc 362 accepted

363 5. Thomsen BR, Hyldig G, Taylor R, Blenkiron P, Jacobsen C (2017) Odour Detection Threshold 364 Determination of Volatile Compounds in Topical Skin Formulations. Eur J Lipid Sci Technol $365 \quad$ submitted

366 6. Thomsen BR, Hyldig G, Taylor R, Gregory J, Blenkiron P, Jacobsen C (2016) Determination of 367 threshold values of lipid oxidation products in skin care products. In: International Symposium 368 on Lipid Oxidation and Antioxidants: PO-18. Porto, Portugal

369 7. Let MB, Jacobsen C, Meyer AS (2005) Sensory stability and oxidation of fish oil enriched milk $370 \quad$ is affected by milk storage temperature and oil quality. Int Dairy J 15:173-182

371 8. Let MB, Jacobsen C, Sørensen ADM, Meyer AS (2007) Homogenization conditions affect the 372 oxidative stability of fish oil enriched milk emulsions: Lipid oxidation. J Agric Food Chem $373 \quad 55: 1773-1780$

$3749 . \quad$ McClements DJ (2005) Food Emulsions - Principles, Practices, and Techniques. London, UK: 375 CRC Press:1-26, 167-525

376 10. McClements DJ, Decker EA (2000) Lipid Oxidation in Oil-in-Water Emulsions: Impact of 377 Molecular Environment on Chemical Reactions in Heterogeneous Food Systems. J Food Sci $378 \quad 65: 1270-1282$ 
379 11. Schultz S, Wagner G, Urban K, Ulrich J (2004) High-pressure homogenization as a process for 380 emulsion formation. Chem Eng Technol 27:361-368

381 12. Waraho T, Mcclements DJ, Decker EA (2011) Mechanisms of lipid oxidation in food 382 dispersions. Trends Food Sci Technol 22:3-13

383 13. Heinrichs V, Thum O (2005) Biocatalysis for the production of care specialties. Lipid Technol $384 \quad 17: 82-87$

385 14. Garbossa WAC, Maia Campos PMBG (2016) Euterpe oleracea, Matricaria chamomilla, and 386

15. Bligh WJ, Dyer EGB (1959) A rapid method of total lipid extraction and purification. Can J 389

390

17. Shantha NC, Decker EA (1994) Rapid, sensitive, iron-based spectrophotometric methods for 393

18. Thomsen BR, Yesiltas B, Sørensen A-DM, Hermund DB, Glastrup J, Jacobsen C (2016) 395

19. Safafar H, Hass MZ, Møller P, Holdt SL, Jacobsen C (2016) High-EPA biomass from Nannochloropsis salina cultivated in a flat-panel photo-bioreactor on a process water-enriched growth medium. Mar Drugs 14:144-153 Comparison of Three Methods for Extraction of Volatile Lipid Oxidation Products from Food Matrices for GC-MS Analysis. J Am Oil Chem Soc 93:929-942

20. Lu FSH, Nielsen NS, Baron CP, Jacobsen C (2012) Oxidative degradation and non-enzymatic browning due to the interaction between oxidised lipids and primary amine groups in different marine PL emulsions. Food Chem 135:2887-2896

21. Porter NA, Caldwell SE, Mills KA (1995) Mechanisms of free radical oxidation of unsaturated lipids. Lipids 30:277-290

405 22. Frankel EN (1084) Lipid oxidation: Mechanisms, products and biological significance. J Am 406 Oil Chem Soc 61:1908-1917 
407 23. Buttery RG, Turnbaugh JG, Ling LC (1988) Contribution of volatiles to rice aroma. J Agric

$408 \quad$ Food Chem 36:1006-1009

409 24. Venkateshwarlu G, Let MB, Meyer AS, Jacobsen C (2004) Chemical and Olfactometric

410 Characterization of Volatile Flavor Compounds in a Fish Oil Enriched Milk Emulsion. J Agric

$411 \quad$ Food Chem 52:311-317

412 25. Jungermann E, Sonntag NOV (1991) Glycerine: A Key Cosmetic Ingredient. New York, USA:

$413 \quad$ Marcel Dekker

414 26. MacManus-Spencer LA, Tse ML, Klein JL, Kracunas AE (2011) Aqueous photolysis of the $415 \quad$ organic ultraviolet filter chemical octyl methoxycinnamate. Environ Sci Technol 45:3931-3937

416 27. Widhalm JR, Dudareva N (2015) A familiar ring to it: Biosynthesis of plant benzoic acids. Mol $417 \quad$ Plant 8:83-97

418 28. Dellagreca M, Iesce MR, Previtera L, Purcaro R, Rubino M, Zarrelli A (2008) Lignans by 419 photo-oxidation of propenyl phenols. Photochem Photobiol Sci 7:28-32

420 29. Murthy RS, Bio M, You Y (2009) Low energy light-triggered oxidative cleavage of olefins. $421 \quad$ Tetrahedron Lett 50:1041-1044

422 30. Matsumoto, Masakatsu Kobayashi H, Matsubara J, Watanabe N, Yamashita S, Oguma D, 423 Kitano Y (1996) Effect of allylic oxygen on the reaction pathways of singlet oxygenation:

424 Selective formation of 1,2-dioxetanes from 1-alkoxymethyl-2-aryl-1-tert-butyl-2425 methoxyethylenes. Tetrahedron Lett 43:1319-1323

426 31. Brachais CH, Huguet J, Bunel C, Brachais L (1999) Identification of small molecules formed 427 from polymethyl glyoxylate degradation in vitro. Polym Degrad Stab 64:243-249

428 32. Rayne S, Forest K (2016) Carboxylic acid ester hydrolysis rate constants for food and beverage 429 aroma compounds. Flavour Fragr J 31:385-394

430 33. GSK (2017) Assessment of the human safety impact of the volatiles. GSK, Brentford, UK 

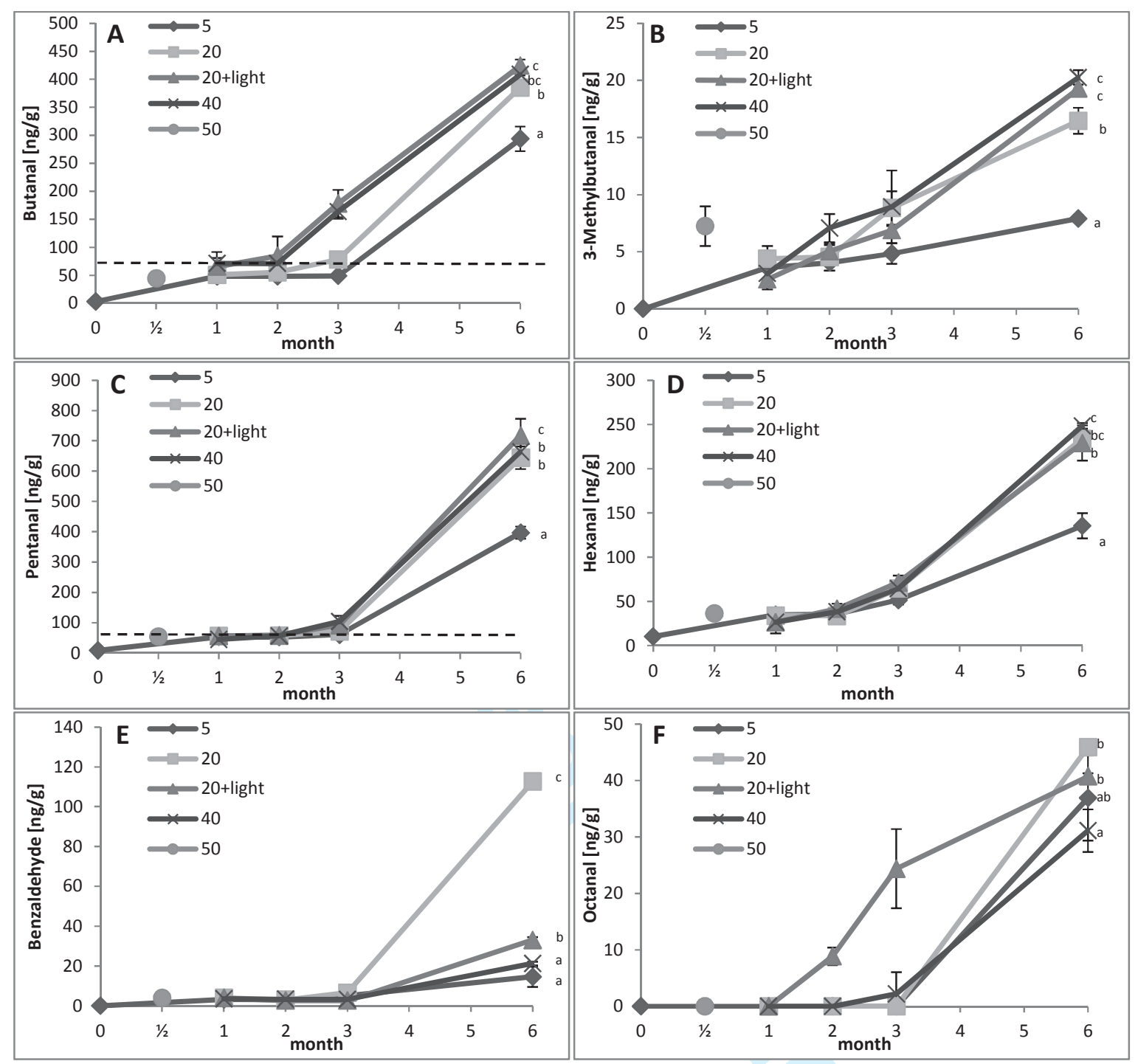

Figure 1. Aldehydes increasing in PSCF during 6 months of storage at $5^{\circ} \mathrm{C}(\diamond), 20^{\circ} \mathrm{C}(), 20^{\circ} \mathrm{C}$ with exposure to light $(\triangle)$, $40^{\circ} \mathrm{C}(\times)$ and $50^{\circ} \mathrm{C}(\mathrm{O})$. The dotted line indicates the odor detection threshold value (butanal and pentanal). The development of A) butanal, B) 3-methylbutanal, C) pentanal, D) hexanal, E) benzaldehyde and F) octanal during storage [ng/g]. Results are presented as average $+/-\mathrm{SD}$ and $\mathrm{N}=\mathbf{3}$. Significance differences at $\mathbf{0 . 0 5}$ level are only marked for the last sampling point. 

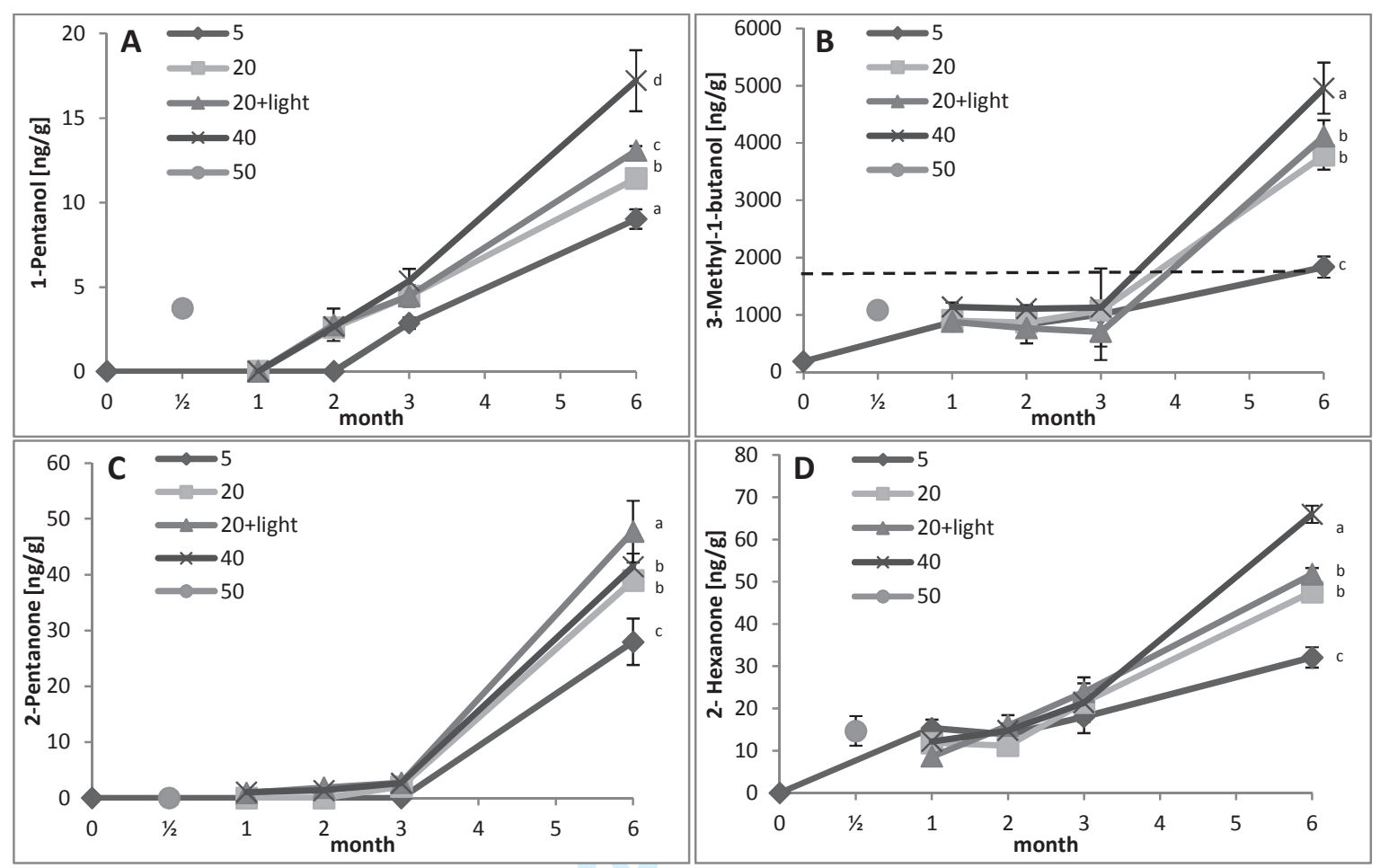

Figure 1. Alcohols and ketones increasing in the PSCF during the 6 months of storage at $5^{\circ} \mathrm{C}(\diamond), 20^{\circ} \mathrm{C}(), 20^{\circ} \mathrm{C}$ with exposure to light $(\triangle), 40^{\circ} \mathrm{C}(\times)$ and $50^{\circ} \mathrm{C}(\odot)$. The dotted line is added for the exact threshold value (3-methyl-1-butanol). The development of A) 1-pentanol, B) 3-methyl-1-butanol, C) 2-pentanone, and D) 2-hexanone during storage [ng/g]. Results are presented as average $+/-\mathrm{SD}$ and $\mathrm{N}=3$. Significance differences at $\mathbf{0 . 0 5}$ level are only marked for the last sampling point. 
Figure 3. Volatile compounds [ng/g] present in raw materials during the 3-month storage at $40^{\circ} \mathrm{C}$. A) rice bran wax and $\mathrm{B}$ ) glycerine. Results are presented as average $+/-\mathrm{SD}$ and $\mathrm{N}=3$. 
Figure 4. Volatile compounds [ng/g] present in skin texture modifying and skin conditioning raw materials during the 3month storage at $40^{\circ} \mathrm{C}$. A) PMEA and B) isostearyl isostearate. Results are presented as average +/- SD and N=3. 
Figure 5. Volatile compounds [ng/g] present in UV filter raw materials during the 3 months of storage at $40^{\circ} \mathrm{C}$. A) $\mathrm{UV}^{\mathrm{a}}$ benzoate, B) UV triazine, and C) UV cinnamate. Results are presented as average $+/-\mathrm{SD}$ and $\mathrm{N}=3$. 
Journal of the American Oil Chemists

Page 36 of 39

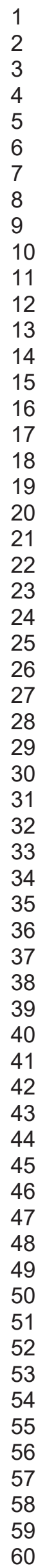


2

3

4

5

6

7

8

9

10

11

12

13

14

15

16

17

18

19

20

21

22

23

24

25

26

27

28

29

30

31

32

33

34

35

36

37

38

39

40

41

42

43

44

45

46

47

48

49

50

51

52

53

54

55

56

57

58

59

60

Table 1. Sample preparation, collection conditions and water evaporation applied for collection of volatile compounds from PSCF and raw materials.

\begin{tabular}{|c|c|c|c|}
\hline Samples & Preparation & Collection & Evaporation \\
\hline PSCF & $\begin{array}{l}1 \mathrm{~g} \text { sample. } \\
\text { Incubation at } \\
45^{\circ} \mathrm{C} \text { for } 5 \mathrm{~min} .\end{array}$ & $\begin{array}{l}50 \mathrm{~mL} / \mathrm{min} \text { at } \\
45^{\circ} \mathrm{C} \text { for } 10 \\
\min \end{array}$ & $\begin{array}{l}50 \mathrm{ml} / \mathrm{min} \text { at } \\
25^{\circ} \mathrm{C} \text { for } 22 \\
\text { min. }\end{array}$ \\
\hline $\begin{array}{l}\text { Rice bran wax } \\
\text { Glycerine } \\
\text { Isostearyl isostearate } \\
\text { UV cinnamate }\end{array}$ & $\begin{array}{l}1 \mathrm{~g} \text { sample. } \\
\text { Incubation at } \\
60^{\circ} \mathrm{C} \text { for } 4 \mathrm{~min} .\end{array}$ & $\begin{array}{l}50 \mathrm{~mL} / \mathrm{min} \text { at } \\
60^{\circ} \mathrm{C} \text { for } 20 \\
\min \end{array}$ & - \\
\hline $\begin{array}{l}\text { PMEA } \\
\text { UV triazine } \\
\text { UV benzoate }\end{array}$ & $\begin{array}{l}1 \mathrm{~g} \text { of sample and } \\
\text { water were mixed } \\
(1: 1) . \text { Incubation } \\
\text { at } 45^{\circ} \mathrm{C} \text { for } 5 \text { min. }\end{array}$ & $\begin{array}{l}50 \mathrm{~mL} / \mathrm{min} \text { at } \\
45^{\circ} \mathrm{C} \text { for } 10 \\
\min \end{array}$ & $\begin{array}{l}50 \mathrm{ml} / \mathrm{min} \text { at } \\
25^{\circ} \mathrm{C} \text { for } 22 \\
\text { min. }\end{array}$ \\
\hline
\end{tabular}


Table 2. Description of difference scale.

\begin{tabular}{|l|l|}
\hline$\underline{\text { DOD Scale }}$ & Description of Difference \\
\hline 1 & No differences in character or intensity noted \\
\hline 2 & $\begin{array}{l}\text { Reasonably sure difference exists, though difference may be too } \\
\text { subtle to accurately describe }\end{array}$ \\
\hline 3 & $\begin{array}{l}\text { Definite difference, can describe difference with reasonable } \\
\text { surety }\end{array}$ \\
\hline 4 & $\begin{array}{l}\text { Product or material out of expected range. Moderate or large } \\
\text { intensity differences or ANY character differences. }\end{array}$ \\
\hline 5 & $\begin{array}{l}\text { Outside normal range. Large intensity and/or character } \\
\text { differences. }\end{array}$ \\
\hline
\end{tabular}

Note: DOD = Degree of Difference 
Table 3. Summary of volatile compounds present in both PSCF and raw materials. $+=$ present, $++=$ present above threshold value $(5,6)$ in raw material (only available for butanal, pentanal and 3-methyl-1-butanol), and - = absent.

\begin{tabular}{|c|c|c|c|c|c|c|c|c|c|c|}
\hline $\begin{array}{l}\text { Volatile compounds/ } \\
\text { Raw material }\end{array}$ & 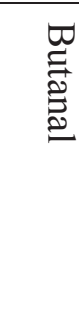 & 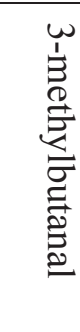 & $\underset{己}{\stackrel{0}{Q}}$ & 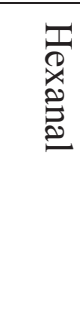 & 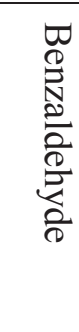 & 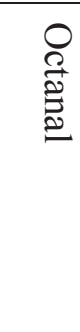 & 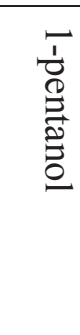 & 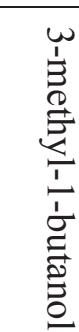 & 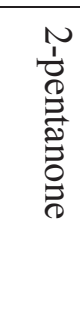 & 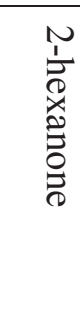 \\
\hline Rice bran wax & + & + & ++ & + & + & + & + & - & + & + \\
\hline Glycerine & + & + & + & + & + & - & - & + & - & + \\
\hline Isostearyl isostearate & ++ & + & ++ & + & - & + & + & + & + & + \\
\hline PMEA & + & - & ++ & + & + & + & - & - & + & + \\
\hline UV cinnamate & - & + & + & - & + & + & - & ++ & - & - \\
\hline UV triazine & + & - & + & + & + & + & - & - & - & + \\
\hline UV benzoate & + & + & + & + & + & + & - & - & - & + \\
\hline
\end{tabular}

